\title{
DA INTELIGIBILIDADE TEÓRICA À RACIONALIDADE ÉTICA EM LEVINAS
}

\author{
FROM THEORETICAL INTELLIGIBILITY AT ETHICS RATIONALITY \\ LEVINAS
}

\author{
MARCOS ALEXANDRE ALVES \\ (Centro Universitário Franciscano e Faculdade Palotina, Brasil)
}

\begin{abstract}
RESUMO
O texto indaga acerca do núcleo das confrontações do pensamento contemporâneo, para mostrar qual é o lugar que corresponde, nesse contexto, à Levinas. Neste sentido, mostraremos, em primeiro lugar, o motivo principal pelo qual, tem-se produzido, nos últimos anos, uma revalorização do pensamento de Levinas, a saber, a virada ética contemporânea; em segundo lugar, ilustraremos uma das noções básicas da proposta filosófica levinasiana, que se encontra em íntima relação com os problemas que o pensamento contemporâneo tem desenvolvido: racionalidade ética como abertura à diferença não-indiferente - alteridade.

Palavras-chave: Inteligibilidade teórica. Racionalidade ética. Alteridade. Diferença. Virada ética.
\end{abstract}

\begin{abstract}
This paper inquires about the core of the confrontations of contemporary thought, to show which is the place that corresponds in this context to Levinas. In this sense, we will show, first, the main reason has been produced in recent years, a revaluation of Levinas's thought, namely the contemporary ethical turn, secondly, illustrate one of the basics of the proposal Levinasian philosophical, which is in close relation to the problems that contemporary thinking has developed: ethical rationality and openness to difference non-indifferent - otherness.

Keywords: Rationality ethics. Theoretical intelligibility. Otherness. Difference. Ethical turn.
\end{abstract}

\section{Introdução}

Simon Critchley assinalou, acertadamente, em sua apresentação ao volume, The Cambridge Companion to Levinas (2002), que durante as duas últimas décadas do Séc. XX observamos a uma revalorização do pensamento de Levinas. Essa revalorização, inclusive, superou os limites não só da França, mas também as demarcações próprias de escolas filosóficas como demonstra o fato de que falam de Levinas, filósofos do âmbito da filosofia analítica, do pragmatismo ou da teoria crítica. Esses aspectos tornam legítimo e oportuno perguntarmo-nos pelo alcance do protagonismo tardio de Levinas e pelas causas que o motivaram. As causas são bem conhecidas de todos e nos limitamos a apenas enumerá-las. Depois da hegemonia do pós-estruturalismo dos anos 60-70, se empreendeu uma volta para a ética e filosofia política e isso evidencia um interesse crescente pelos trabalhos de Levinas. Também ocorreu uma volta à fenomenologia nos anos 80-90 e uma renovação do interesse pelos temas religiosos (CRITCHLEY, 2002, p. 1-6). Parece-nos, contudo, que não é suficiente apenas constatar a projeção internacional do pensamento de Levinas. Por isso nossa intenção, aqui, é indagar acerca do núcleo das confrontações do pensamento contemporâneo para 
mostrar qual é o lugar que corresponde, nesse contexto, à Levinas. Para tal empreendimento, propomo-nos, nesse texto, em primeiro lugar, mostrar o motivo principal pelo qual, desde nosso ponto de vista, tem-se produzido uma revalorização do pensamento de Levinas nos últimos anos, a saber, a virada ética contemporânea; em segundo lugar, pretendemos ilustrar uma das noções básicas da proposta filosófica levinasiana, que se encontra em íntima relação com os problemas que o pensamento contemporâneo tem desenvolvido uma grande sensibilidade: estamos nos referindo a uma racionalidade aberta a uma diferença nãoindiferente - alteridade.

\section{Levinas e a virada ética contemporânea}

Tornou-se pacificamente admissível que a virada ética da filosofia contemporânea se consolida na segunda metade dos anos 80 do Séc. XX. Produz-se sob a forma de uma revalorização da reflexão ético-prática como solução à crise do esgotamento da racionalidade teórica (SEBBAD, 2009, p. 33-35). A razão técnico-científica excluiu a racionalidade prática do âmbito da razão; mas por sua vez, essa razão instrumental que se auto-apresentava como a única razão, na medida em que elaborava uma teoria generalizadora, esgotou-se em sua intenção totalizadora. Portanto, na medida em que se pretende salvar a razão do naufrágio, e com ela a própria filosofia, só resta apelar à racionalidade prática.

Este movimento de reabilitação da racionalidade prática começa na Alemanha por volta dos anos 60 e se pode considerar como uma continuação do debate, que gira em torno da tradição fenomenológico-existencial, da relação entre as ciências da natureza e as ciências do espírito e a filosofia. Mesmo que comece como uma recuperação do interesse filosófico pelas temáticas da ação, acaba por tomar a forma de uma reabilitação da filosofia enquanto filosofia. Ou seja, a reabilitação da racionalidade prática possui uma precisa relevância "metafilosófica" e uma clara entonação polêmica com relação ao imperialismo da razão técnicoprática: a racionalidade prática volta a emergir como razão distinta da racionalidade moderna, instrumental (D'AGOSTINI, 2000, p. 220).

Especificamente, nessa virada ético-prática convergem contribuições filosóficas de orientações diversas como é o caso da hermenêutica, da teoria crítica, da filosofia analítica ou os desenvolvimentos pós-modernos. Essa coincidência do pensamento contemporâneo, apesar de suas variações, responde e surge como uma espécie de rebelião frente à racionalidade instrumental moderna, que se encontra no fundamento dessa virada, e não em menor medida 
alentados por uma recuperação da racionalidade prática de Aristóteles e Kant. Ainda que, por um lado, desde o ponto de vista da teoria crítica Habermas e Apel defendem um novo universalismo por meio de uma extensão da noção tradicional moderna de razão, apelando para o âmbito do público ou do Estado; por outro, Gadamer e Bubner propugnam uma pluralização da idéia de razão por meio de uma racionalidade contextual-imanente à práxis, apelando para a esfera do ethos. Mas esse mesmo movimento pode ser vislumbrado também nos autores contemporâneos que a partir da década de 80 passam do fim dos valores, da morte de Deus e do homem a um compromisso ético cada vez mais pronunciado. Também, pode-se observar nos últimos anos, nos filósofos analíticos uma dedicação às questões ético-políticas em detrimento do interesse por questões epistemológicas (D’AGOSTINI, 2000, p. 218-226).

Pode-se, assim, falar de uma intenção comum na linha de unir a ética a uma nova maneira de teorizar não generalizadora. Por isso, a virada ético-política dos pensadores contemporâneos tem um ponto de intersecção com a hermenêutica e seus discípulos e continuadores do projeto de ampliação da racionalidade.

Por conseguinte, propomo-nos mostrar agora que no pensamento de Levinas urge uma peculiar proposta de ampliação da racionalidade ética, e nisso reside uma fonte de inspiração para os pensadores contemporâneos. A nossa hipótese de trabalho é que na proximidade de posturas, subjaz a influência que Levinas exerce nos pensadores de âmbito contemporâneo, o que possibilita abrir caminhos de execução éticos.

Levinas não se limitou a uma crítica à absolutização da racionalidade teórica, própria à filosofia moral, mas acreditamos que em seu pensamento há também uma alternativa. Essa alternativa envolve os elementos iniciais e as primeiras noções de uma racionalidade ética como complemento da racionalidade teórica. Em nosso entendimento, esse é um dos pontos do pensamento de Levinas que lhe conferem especial atualidade (SEBBAD, 2009, p. 39). Nesse intuito, o itinerário que seguiremos, ora adiante, implica: em primeiro lugar, mostrar o modo como Levinas denuncia a insuficiência da racionalidade teórica; em segundo lugar, analisar o tipo de racionalidade que Levinas propõe como complemento da racionalidade teórica, cuja novidade consiste na abertura à alteridade.

\section{Os limites da racionalidade teórica}

A finalidade desse artigo além de mostrar os motivos da reavaliação da obra de Levinas, que permitem falar de uma eficaz influência deste no pensamento contemporâneo, no que toca à defesa da tese que propugna a ética como racionalidade aberta à alteridade, e 
não em expor sistematicamente sua noção de racionalidade, queremos, ainda que brevemente, considerar o que entende Levinas por racionalidade teórica.

Levinas identifica a racionalidade teórica com a objetivação, e considera que o conhecimento ou a objetivação implica a perda da alteridade daquilo que se conhece. $\mathrm{O}$ conhecimento formaliza, ou melhor, só conhece formas, e nessa restrição ao formal a alteridade fica neutralizada. Não só isto, mas o puro ater-se à formalidade explica que a própria identificação da sinopse conceitual seja uma violência (LEVINAS, 1991, p. 17).

Por esse motivo, Levinas conclui que o conhecimento objetivo é essencialmente violento, porque não é capaz de entrar em contato com a realidade em sua individualidade; só a alcança em sua generalidade. A violência consiste em recusar a individualidade de um ser atingindo-o como elemento do próprio cálculo e como caso particular de um conceito. Levinas considera que a violência do conhecimento objetivo consiste em abordar o ser, para apoderar-se dele, a partir do que não é realmente ele. Essa relação de domínio sobre as coisas consiste em não abordá-las nunca em sua individualidade. A coisa em sua individualidade, não é realmente acessível senão que a partir da generalidade, a partir do universal. Apropriamo-nos das coisas a partir de seu conceito (LEVINAS, 1994, p. 49). Segundo Levinas, como o conhecimento procede por formalizações não pode aceder à realidade, isto é, à individualidade, o único que existe. Enquanto se recorre a uma mediação já se tem perdido o contato direto com a realidade.

Esse breve esboço dos limites da racionalidade teórica, tal qual Levinas os apresenta, explica que um dos principais eixos de seu pensamento consiste no problema da abertura da imanência. De fato, a investigação levinasiana se concentra na busca de um caminho para sair da imanência, por isso que a noção de transcendência articula toda a sua filosofia (LEVINAS, 1994, p.60). Porém, Levinas nos alerta que não é qualquer caminho que se apresenta como apto para sair da imanência; ou seja, segundo ele, nem o idealismo nem o realismo o conseguem, pois essas duas posturas, apesar de suas diferenças, coincidem em propor a saída da imanência através da transcendência cognoscitiva (LEVINAS, 1993, p. 22). Precisamente, nesse ponto, encontra-se o núcleo que sujeita a problemática abordada por Levinas: a incapacidade do conhecimento para alcançar uma autêntica transcendência.

Assim, ao analisarmos o modo como Levinas trata o conhecimento, tornar-se evidente que, filho de seu tempo, alimenta uma profunda desconfiança para com a captação cognoscitiva. Como tantos outros pensadores contemporâneos, perplexos pelos paradoxos a que conduz um conhecimento representacionista, de que a filosofia moderna tem feito 
verdadeiro alarde, mas, por sua vez, incapazes de superar a eterna aporia que ressurge desde o momento em que o conhecimento é interpretado como especulação, Levinas também se soma à tendência contemporânea de receio para o conhecimento.

Esse receio vem precedido pela violência que caracteriza a dominação cognoscitiva (LEVINAS, 1999, p. 165). Na realidade, quando Levinas analisa o conhecimento está pensando no conhecimento como domínio da natureza, próprio da modernidade. A alteridade do outro ao entregar-se ao sujeito cognoscente, em sua generalidade, está ante o eu como objeto efetivo, ou seja, como caso de uma regra geral. A realidade deixa de se opor ao eu para passar a ser sua aliada, mas nessa passagem perde o que tinha de realidade porque adquiriu a máxima maleabilidade: o eu impõe algumas estruturas à realidade natural para dominá-la cientificamente (LEVINAS, 1999, p. 201-216). Levinas chega a caracterizar o conhecimento como uma criação e destruição, e o objeto como resultado. Desse modo, Levinas critica a compreensão do ser como realidade efetiva que conduz à substituição do paradigma da verdade pelo paradigma da certeza. Por detrás dessa interpretação do conhecimento em termos de dominação, encontra-se o problemático estatuto da mediação cognoscitiva que a filosofia moderna não pode resolver desde suas coordenadas representacionistas.

Entendida como substituição de outrem, a representação moderna nos fala de um objeto mediatizado, de modo que, para constatar a veracidade cognoscitiva da mediação objetual é impossível evitar o regresso ao infinito em uma cadeia de mediações sucessivas que serviriam para confirmar a veracidade da mediação anterior em sua correlação com a coisa. É amplamente conhecido que para evitar esse espinhoso assunto, na filosofia moderna, através de suas distintas variações, o objeto acaba sendo constituído na consciência (LEVINAS, 1999, p. 156). O que permite falar, se não da verdade, ao menos da certeza dessas representações. Do que não há dúvida alguma é da presença do objeto na consciência e da adequação entre ambos. Tudo o que explica a razão última pela qual, nessa perspectiva, o conhecimento acaba sendo um domínio científico da natureza. Domínio e mediação andam lado a lado.

Pode-se, certamente, arguir que há outro modo de entender a mediação cognoscitiva que não incorre em dominação. Trata-se de uma mediação que imediatiza e que é a própria do objeto formal: aquele que não dá notícias de si e cuja entidade se esgota na pura referencialidade ou remissão à coisa. Mas Levinas não tem em conta essa noção medieval; para ele, o assunto se debate nos seguintes termos: mediação ou imediação; dominação cognoscitiva ou respeito da alteridade (LEVINAS, 1999, p. 28-34).

Por conseguinte, Levinas, na busca por uma saída da imanência, postula uma alternativa à transcendência cognoscitiva. Por um lado, não renuncia em penetrar na 
intimidade do real; por outro lado, tampouco considera que o conhecimento objetivo - a abstração - permite uma postura distinta ao domínio da própria natureza da filosofia moderna que se acaba de expor. Portanto, não lhe resta outra solução a não ser prescindir do conhecimento para sair da imanência. Levinas entende que, uma vez ocorrendo objetivação ou conhecimento, a transcendência do conhecido não pode ser salvaguardada. $\mathrm{O}$ conhecimento enquanto adequação ou conhecimento objetivante é um saber que implica um conhecimento que só pode conhecer, na medida em que dissolver a alteridade. Em seus escritos esse conhecimento aparece ligado à ontologia e às vezes com um significado quase sinônimo, pois a idéia de ser é aquela que dá plenamente conta da adequação, e, portanto, não há ontologia sem objetivação (LEVINAS, 1994, p. 52). Contudo, Levinas não renuncia à saída da imanência, isso o conduz na busca de outro caminho que seja mais cognoscitivo que o conhecimento, por meio do qual seja possível uma relação com a alteridade que não anule sua transcendência (LEVINAS, 2000, p. 21-39).

Nesse caminho alternativo ao conhecimento se localiza a questão ética. De certa forma, a obra de Levinas vai adquirindo progressivamente a fisionomia de uma fundamentação da ética, porém não é menos verdade que não é possível a fundamentação da ética desde uma filosofia da imanência, ou a fundamentação de uma ética que respeite a alteridade indiscernível do outro (LEVINAS, 1993, p. 55-66). Porque éticas existem, e muitas, mas o escândalo que provoca sua ineficácia, e no caso especial de Levinas, tendo em vista os genocídios do civilizado mundo ocidental durante o séc. XX, torna-se necessária uma fundamentação que conjugue definitivamente a mediação do mal para alcançar o bem: mediação justificável, inclusive em nome do progresso e da civilização. Por esse motivo, o presente artigo não é um estudo mais da ética de Levinas, mas, adotando um gesto próprio de Levinas, queremos dar um passo mais atrás para averiguar onde se localiza em nosso autor o ponto de apoio de uma ética em que o bem não está mediado por nada. A contestação de Levinas segue na linha de que esse suporte só se encontra quando se alcança uma transcendência que seja irredutível à imanência, de modo que o sujeito não possa a partir de si medir a totalidade do real, do mundo e dos outros.

Efetivamente, Levinas, para evitar a mediação que dissolve a alteridade, propõe uma alternativa tanto para o idealismo quanto para o realismo, que consiste em salvaguardar a transcendência na linha de uma imediatização que imediatiza. Nesse marco se inscreve a defesa da existência na sensibilidade de uma significação que é irredutível ao conhecimento, a saber, a proximidade. Uma significação que significa, segundo a expressão do próprio 
Levinas:

\begin{abstract}
Passividade mais radical do que aquela do efeito numa série causal, passividade aquém da consciência e do saber, mas igualmente aquém da inércia das coisas repousando sobre si mesma, como substâncias e opondo sua natureza, causa material, a toda atividade. Tratar-se-ia de uma passividade referida ao reverso do ser, anterior ao plano ontológico em que o ser se põe como natureza, referida a anterioridade ainda sem exterioridade da criação, à anterioridade metafísica (LEVINAS, 1993, p. 89-90).
\end{abstract}

Ou seja, trata-se de uma passividade mais passiva que qualquer passividade, porque se distancia do sujeito transcendental constituinte (LEVINAS, 1993, p. 16). Levinas propõem uma passividade tão passiva que deve ser mais passiva que a recepção e, por isso, consiste em um traumatismo, que em nenhum momento se assume, simplesmente se padece. Essa significação não poderia ter a forma de um enunciado dóxico em que reapareceriam os fantasmas da adequação e do imanentismo. O sujeito encontra a alteridade sem absorvê-la porque o outro significa através de uma súplica. A imediatez do contato na proximidade significa uma ordem que perturba completamente o eu. Em definitivo, Levinas propõe como solução à imediatez da perturbação ética (LEVINAS, 1987, p. 166), que não é um conhecimento objetivo, portanto não dissolve a transcendência; mas nem por isso deixa de ser um cognoscitivo. A perturbação ética do eu (subjetividade) consiste em um movimento mais cognoscitivo que o conhecimento: o Desejo que envolve a idéia de infinito, descoberta no rosto do outro que se aproxima (LEVINAS, 2000, p. 37). Esta síntese do pensamento de Levinas também explica a peculiar fisionomia de seu pensamento, que vai tomando as diretrizes de uma alternativa ética ao conhecimento; essa alternativa, sem deixar de ser à sua maneira cognoscitiva, e ademais fundadora do conhecimento, deve permitir uma imediata aproximação ao outro sem se apropriar de sua transcendência. É uma aproximação sem dominação porque consiste em uma imediatez absoluta.

\title{
Ética: racionalidade aberta à alteridade
}

Mostramos até o momento as razões pelas quais Levinas se propõe a explorar uma saída da imanência, por meio de um caminho diferente àquele do conhecimento, assim como a constituição ética dessa alternativa levinasiana se mostra contrária à transcendência cognoscitiva. Isso não só afeta o modo como é possível o acesso à alteridade, mas também o acesso ao próprio eu, que Levinas postula como chave ética. Levinas propõe, concretamente, o acesso ao próprio eu através da diferença intrínseca que constitui o eu enquanto finito. Esse modo de aceder ao eu supõe imediatamente colocar o sujeito em uma situação ética. $\mathrm{O}$ eu, 
precisamente, por ser finito é diferente, leva em seu seio um traço da alteridade que o torna constitutiva e em sua própria medida não pode desinteressar-se dela. A diferença não o torna indiferente porque a diferença o constitui a si mesmo e o interpela. Ao contrário da filosofia de Heidegger, Levinas entende que a finitude do eu tem como conseqüência a não-indiferença ética em toda a sua radicalidade (LEVINAS, 1987, p.113-123).

A crise da filosofia se encontra, para Levinas, em sua incapacidade para responder aos seus próprios critérios de sentido (LEVINAS, 2002, p. 157). Particularmente, para resolver essa dificuldade, ele se empenha em mostrar a independência da inteligibilidade ética com relação ao pensamento teorético (LEVINAS, 2002, p. 235). Existe outro uso da razão, mais além do teorético, como o fato de que a racionalidade também pode se chamar justificação e não apenas demonstração. Nisso coincidem com ele os autores pós-modernos, porém Levinas não renuncia a possibilidade de uma ética, ou seja, a possibilidade de uma razão prática (LEVINAS, 2002, p. 238).

Pois bem, como assinalado acima, se esta racionalidade alternativa é ética, deve incluir o encontro com a alteridade, o que Levinas denomina proximidade. Portanto, a razão teórica generalizadora tem seu limite na proximidade, que é um encontro cognoscitivo, não generalizador. A proximidade significa uma razão anterior à tematização; é uma razão préoriginal que não procede de nenhuma iniciativa do sujeito. Segundo Levinas, à inteligibilidade como logos racional se opõe a inteligibilidade como proximidade (LEVINAS, 1987, p. 209-210). A proximidade mostra a diferença entre eu e o outro e se inscreve como responsabilidade porque essa diferença me constitui e, nessa medida, me impede de ser indifernte a ela (LEVINAS, 1987, p. 210-214). Portanto, para Levinas o psiquismo é o outro dentro do mesmo sem alienar o mesmo.

Levinas se serve da metáfora ${ }^{1}$ da insônia para mostrar como atua essa razão diferente. $\mathrm{Na}$ identidade do estado de consciência presente a ele mesmo, há uma diferença entre o Mesmo e o Mesmo que a identidade não pode chegar a reduzir. Levinas não dirá que há uma diferença, senão que vigília uma diferença, ou seja, é a vigília da insônia. (LEVINAS, 2002, p. 52). A insônia ou a vigília é o despertar do sono da Razão entendida como consciência. A insônia é uma ruptura produzida por uma transcendência que dilacera a imanência. É uma consciência sem intencionalidade. Desde o ponto de vista da insônia a subjetividade é entendida como submetimento a um Outrem totalmente transcendente (LEVINAS, 2002, p. 53). O Mesmo despertando-se sempre de si mesmo; trata-se de uma razão que não se limita à lucidez. Ao contrário da filosofia moral iluminista que situa na universalidade das leis morais 
a garantia da moralidade. O desprezo pelo particular é a desatenção ao vitalismo moral. No século XX as herdeiras da ética universalista são as éticas procedimentalistas e o consequencialismo moral, que de algum modo quer incorporar os efeitos reais à decisão pessoal. Todas elas reclamam outra ética.

Levinas, nesse contexto, se propõe a dar conta da necessidade de preconizar uma alternativa à ética universalistas por meio da sua proposta de uma racionalidade nova, diferente ou mais profunda que a racionalidade do logos, que consiste na relação com uma transcendência (LEVINAS, 2002, p. 167); é na proximidade do infinito onde o bem começa a ter significado; proximidade que confere um sentido à duração do viver. Assim Levinas encontra vestígios, na história da filosofia, que aludem ao paradoxo dessa racionalidade que se move no âmbito da significatividade não-ontológica. Essa é a função do intelecto agente aristotélico (LEVINAS, 2002, p. 162). Na proximidade se dissolve o solipsismo da imanência porque se realiza a abertura do receber. O intelecto agente realiza essa abertura, pois uma vez vindo do exterior constitui a atividade soberana da razão sem comprometê-la. O intelecto agente substitui a maiêutica socrática por uma ação transitiva, de modo que a razão, sem possibilidade de renúncia, se encontra em condições de receber (LEVINAS, 2000, p. 38). Levinas não duvida que essa racionalidade não objetivadora, encarnada pelo intelecto agente, é uma perturbação do Mesmo por parte do Outro. Ou seja, nas palavras do próprio Levinas:

\footnotetext{
A paciência do infinito em que a razão é um desconcerto incessante do Mesmo pelo Outro ou a diacronia do Tempo, o que, concretamente, se produz na minha responsabilidade para com outrem ou na ética. Perguntamos se o Outro que se recusa à identificação - ou seja, á tematização e à hipóstase - mas que a filosofia da tradição tentava recuperar na paciência do conceito mediante a metodologia da história como consciência de si, se o Outro não deve ser entendido de modo totalmente diferente nem questionamento do pensamento pelo infinito que ele não poderia abarcar, e no despertar; questionamento e despertar que se invertem em ética da responsabilidade para com outrem; questionamento incessante da quietude ou da identidade do Mesmo. (LEVINAS, 2002, p. 165).
}

O mandato ético surge na in-mediatez dessa racionalidade entendida como proximidade. Trata-se de uma obrigação ética in-mediata, sem generalizações, anterior a uma lei universal. Essa razão não se situa na linha da compreensão, senão na passividade de um receber inassumível. Na proximidade se escuta um mandato, o apresentar-se do Outro significa para o eu uma responsabilidade irrecusável, anterior a todo consentimento livre. $\mathrm{O}$ mandato é o que torna insubstituível o eu, e por isso ele é único. No âmbito do humano a alteridade não é unicamente qualitativa. O homem tem identidade independentemente das qualidades ou características que distingam um eu de Outro. No lugar de ser uma tematização, 
esse pensamento é uma não indiferença pelo Outro. O mandato dessa responsabilidade pelo Outro é a ruptura da Jemeinigkeit heideggeriana. Seu caráter insubstituível remete à responsabilidade que é eticamente vinculante porque procede de uma eleição. O sujeito foi eleito responsável pelo Outro e não pode desvincular-se dessa eleição que é anterior a toda decisão livre (LEVINAS, 1987, p.113).

Essa racionalidade nova entendida como proximidade também produz o desejo do Outro, que pode ser interpretado como uma intencionalidade não-teorética. Não é uma tendência para a verdade, mas para o bem, porque o Desejo se revela como bondade e, nesse sentido, é a origem do sentido. Na proximidade, no contato com o infinito, meio da alteridade do Outro, ocorre o contato com o Bem em um sentido muito preciso: o Bem não me preenche de bens, mas me compele à Bondade (LEVINAS, 1993, p. 95).

\section{Considerações finais}

Intencionamos colocar em relevo que o pensamento de Levinas está muito distante da visão naturalista da ética. O bem não é algo natural, nem inato, mas algo obtido a partir da realidade. Acessa-se ao bem desde o contato com a exterioridade. Assim, há indícios de um tipo de racionalidade que transborda a inteligibilidade teórica porque é capaz de descobrir uma obrigação ética no encontro não-teórico com o Outro. Essa racionalidade oposta à racionalidade teorética, sempre é apresentada por Levinas com características de ultimidade: é prévia a todo o conhecimento posterior, pré-reflexiva, é imediata, não requer um esclarecimento posterior e constitui um limite para a racionalidade teórica. Essas características nos permitem pensar que Levinas está se referindo ao entendimento do primeiro princípio prático. Isso se confirma se recordarmos que Levinas recorre ao intelecto agente aristotélico que obtém a inteligência dos primeiros princípios na mesma realidade (exterioridade) à que se abre. Trata-se de uma penetração do entendimento, não discursiva, na realidade do Outro.

A atualidade dessa proposta filosófica torna-se inédita no mundo da globalização em que convivem todas as diferenças, em ocasiões resvalando-se para uma in-diferenciação progressiva; outras vezes, em meio dos atritos que supõe a luta por seu reconhecimento. Para sair dessa aporia é necessário encontrar um ponto de apoio que não dependa da liberdade do compromisso: algo indeclinável. Ou seja, para Levinas, a alternativa é, ou dirige-nos para a responsabilidade mais além da liberdade, ou para a liberdade do jogo sem responsabilidade. 
A filosofia de Levinas oferece a possibilidade de superar o jogo de irresponsabilidade. Assim o têm visto todos os autores que consideram Levinas uma das fontes de inspiração da recente virada ética do pensamento pós-moderno. Acusados de indiferença ética, os pensadores pós-modernos ensaiam posturas éticas na linha da consideração moral do particular e a revalorização da noção política de justiça. Levinas proporciona a possibilidade de uma diferença não-indiferente, que só é alcançável na medida em que for obtida a ampliação da racionalidade teórica. Há mais que indícios para ver em Levinas um dos inspiradores dessa virada ético-política. 


\section{Notas:}

${ }^{1}$ Para Levinas, metáfora significa: "o remeter à ausência - pode ser considerada como uma excelência que revela de uma ordem totalmente diferente da receptividade pura. A ausência para a qual a metáfora conduz não seria um outro dado, mas ainda futuro ou já passado" (LEVINAS, 1993, p. 24). 


\section{Referências bibliográficas:}

CRITCHLEY, Simon (Org.). The Cambridge Companion to Levinas. Cambridge University Press, 2002.

D'AGOSTINI, F. Analíticos y continentales, guia de la filosofia de los últimos treinta años. Madrid: Ediciones Cátedra, 2000.

BENSUSSAN, Gérard. Ética e experiência: a política em Levinas. Passo Fundo: IFIBE, 2009.

COSTA, Márcio Luis. Levinas: uma introdução. Petrópolis: Vozes, 2000.

FABRI, Marcelo. Desencantando a ontologia. Porto Alegre: EDIPUCRS, 1997.

Fenomenologia e cultura. Porto Alegre: EDIPUCRS, 2007.

FARIAS, André Brayner de et ali (Orgs.). Alteridade e ética: obra comemorativa dos 100 anos de nascimento de Emmanuel Levinas. Porto Alegre: EDIPUCRS, 2008.

LEVINAS, Emmanuel. Altérité et transcendence . Montpellier: Fata Morgana (Le Livre de Poche), 1995.

. De Deus que vem a Idéia. Petropólis: Vozes, 2002.

. De otro modo que ser, o más allá de la esencia. Salamanca: Sígueme, 1987.

. Descobrindo a existência com Husserl e Heidegger. Lisboa: Instituto Piaget,

1999.

. Liberte e commandement . Montpellier: Fata Morgana (Le Livre de Poche),

1994.

. Humanismo do Outro Homem. Petropólis: Vozes, 1993.

. Totalidade e Infinito. Lisboa: edições 70, 2000.

. Transcendência e inteligibilidade. Lisboa: Ed. 70, 1991.

MELO, Nélio Vieira de. A ética da alteridade em Levinas. Porto Alegre: EDIPUCRS, 2003.

PELIZZOLI, Marcelo L. Levinas: a reconstrução da subjetividade. Porto Alegre: EDIPUCRS, 2002.

SEBBAH, Françoais-David. Lévinas. São Paulo: Estação Liberdade, 2009.

SOUZA, Ricardo Timm de. Sentido e Alteridade: Dez ensaios sobre o pensamento de E. Levinas. Porto Alegre: EDIPUCRS, 2000.

. Sujeito, ética e história. Porto Alegre: EDIPUCRS, 1999. 
SUSIN, Luiz Carlos. O homem messiânico: Uma introdução ao pensamento de E. Levinas. Porto Alegre: EST/ Vozes, 1984.

SUSIN, Luiz Carlos e et ali (Orgs.). Éticas em diálogo: Levinas e o pensamento contemporâneo: questões e interfaces. EDIPUCRS, Porto Alegre, 2003. 